
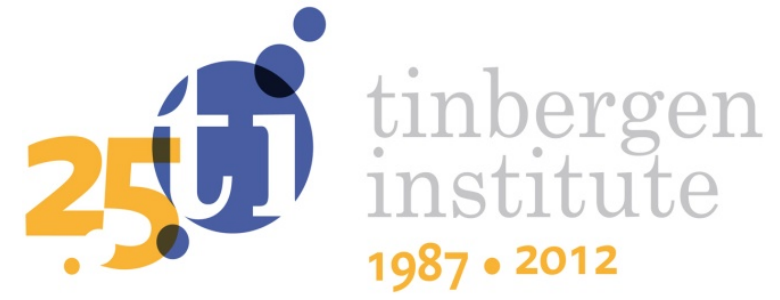

\title{
Congestible Goods and Hoarding: \\ A Test based on Students' Use of University Computers
}

\author{
Martijn B.W. Kobus \\ Jos N. van Ommeren \\ Hans R.A. Koster \\ Piet Rietveld
}

Faculty of Economics and Business Administration, VU University Amsterdam, and Tinbergen Institute. 
Tinbergen Institute is the graduate school and research institute in economics of Erasmus University Rotterdam, the University of Amsterdam and VU University Amsterdam.

More TI discussion papers can be downloaded at http://www.tinbergen.nl

Tinbergen Institute has two locations:

Tinbergen Institute Amsterdam

Gustav Mahlerplein 117

1082 MS Amsterdam

The Netherlands

Tel.: +31(0)205251600

Tinbergen Institute Rotterdam

Burg. Oudlaan 50

3062 PA Rotterdam

The Netherlands

Tel.: +31(0)10 4088900

Fax: $+31(0) 104089031$

Duisenberg school of finance is a collaboration of the Dutch financial sector and universities, with the ambition to support innovative research and offer top quality academic education in core areas of finance.

DSF research papers can be downloaded at: http://www.dsf.nl/

Duisenberg school of finance

Gustav Mahlerplein 117

1082 MS Amsterdam

The Netherlands

Tel.: +31(0)20 5258579 


\title{
Congestible goods and hoarding:
}

\section{a test based on students' use of university computers}

\author{
Martijn B.W. Kobus ${ }^{1}$ \\ Jos N. van Ommeren ${ }^{1,2}$ \\ Hans R.A. Koster $^{1}$ \\ Piet Rietveld ${ }^{1,2}$ \\ ${ }^{1}$ VU University Amsterdam, The Netherlands \\ ${ }^{2}$ Tinbergen Institute, The Netherlands
}

$04 / 17 / 2013$

Abstract. For certain goods, higher levels of congestion imply higher levels of expected future entry costs. This provides current users of the good with an incentive to hoard, that is, to lengthen their duration of good use, in order avoid entry costs later on. We test for hoarding of university computers by students. Endogeneity of congestion is acknowledged by using an instrumental variable approach. Our results indicate that congestion has a strong effect on hoarding behaviour. More specifically, it is shown that the congestion elasticity of computer duration is about 0.57 .

Keywords: congestible goods, hoarding, computer use

Acknowledgements. We thank Richard Arnott, Frank Bruinsma, Donald Shoup, participants of the ERSA 2011 conference, and two anonymous reviewers for valuable suggestions. 


\section{Introduction}

For many congestible goods, the individuals' costs of using the good are an increasing function of number of current users. Important examples include recreational places, public transport, and road transport. ${ }^{1}$ However, for other congestible goods, congestion increases new users' costs of entry, for example through a higher waiting time. Relevant examples include curbside parking places, public housing, and airport landing slots which are allocated using grandfather rights. ${ }^{2}$

In this paper, we focus on the latter group of congestible goods. The demand for these goods, and therefore congestion, is usually strongly autocorrelated over time. For example, if the demand for parking is high at three o'clock in a certain street, it is likely also high one hour later. Current levels of congestion are therefore a signal of future entry costs. Congestion then provides current users with an incentive to lengthen the period of good use, in order to reserve a place for later use. This hoarding strategy receives no attention in the public economics literature (e.g., Atkinson and Stiglitz, 1980; Scotchmer, 2002). The main exception is Arbatskaya et al. (2005) who study hoarding in a model where drivers compete for parking spaces in an all-pay auction, based on the schedule delay costs of arriving earlier than the preferred arrival time. They show that, when there are few parking spaces available, there are substantial welfare costs of hoarding. In general, hoarding results in inefficiencies in the way congestible goods are employed, particularly during peak times.

To the best of our knowledge, there are no empirical papers on hoarding of congestible goods, although there are many anecdotal examples. For example, car drivers have been observed to hoard curbside parking places (Shoup, 2005, p. 443); students have been reported to hoard university computers (Straathof, 2011); airlines have been observed to hoard landing

\footnotetext{
${ }^{1}$ See Gilbert and Hudson (2000), Lyons and Urry (2005), Small and Verhoef (2007), Ohmori and Harata (2008) and Proost and Dender (2008).

${ }^{2}$ See Currie and Yelowitz (2000), Doganis (2002), Shoup (2005), Arnott and Inci (2006); Givoni and Rietveld (2009) and Van Ommeren and Koopman (2011).
} 
slots at airports (Doganis, 2002). For landing slots at airports, the literature focuses on the effect of congestion on current users, but due to grandfather rights, the effect may even be stronger for new users, because incumbent carriers continue to use landing slots that are nonprofitable in the short run (Doganis, 2002; Givoni and Rietveld, 2009).

In the current paper, we test for university computer hoarding by students. Although computers play a very prominent role in modern-day life (and universities spend large amounts of money on ICT-facilities for students), little is known about the way in which computers are used at campuses. Descriptive studies on campus computer use include Sevtsuk et al. (2009); Burke et al. (2008); Henderson et al. (2008); Spennemann et al. (2007) and Kotz and Essien (2005).

In essence, we estimate the effect of computer occupancy rates on computer outflow rate, i.e. the rate at which students stop using a university computer, which is inversely related to the duration of computer use. ${ }^{3}$ Our key assumption to identify hoarding is that students use the current occupancy rate to predict future entry costs. ${ }^{4}$

We emphasise that students may hoard computers even when the occupancy rate of computers is substantially less than one. The main reason is that many students prefer to sit in groups (to work on assignments or for other reasons), and likely aim to avoid a situation where they return to computer rooms and cannot sit together. To illustrate this point, we will show later on that students with similar characteristics are more likely to sit next to each other. As a result, students who prefer to work in groups of two may already have an incentive to hoard when the occupancy rate exceeds about 0.50 (when occupied computers are evenly spread out in each room). For students that prefer to work in a larger group, hoarding may

\footnotetext{
${ }^{3}$ There are also other ways in which the occupancy rate in a computer room may affect the use duration. A high occupancy rate might lead to noise and an unpleasant atmosphere, making computer use less attractive so that sessions become shorter than they would otherwise be. Furthermore, some students may feel uneasy when they realise that there is a queue of people that wish to start computer use, and therefore they might reduce their session length. Our results only show the net result of the various effects of occupancy rates, so we may underestimate the hoarding effect.

${ }^{4}$ In a previous version of this paper, we also extensively examine the effect of occupancy on the inflow. In line with theory, this analysis shows that congestion reduces inflow.
} 
start at even lower levels. Furthermore, because students use current computer occupancy as predictor for future occupancy, students working individually may hoard at moments when occupancy is still relatively low (e.g., 0.70 ), because there may be a substantial risk for them that the occupancy rate is much higher later on when they prefer to return. At the same time, the costs of hoarding a computer may be low for students. For example, a student may leave the computer room for a while without logging off from the computer.

By making use of computer log information, we observe computer use by thousands of students over a long time period. Heterogeneity of students is taken into account by including student fixed effects. Our identification strategy to deal with the endogenous effect of congestion on demand is based on exogenous variation in computer supply (as an instrument we use the number of computers that are reserved for lectures). We will estimate the effect of congestion on computer outflow rate using both linear and semiparametric regression techniques. The results show that hoarding is important: the congestion elasticity of computer duration is about 0.57 . We also investigate alternative explanations for this, but do not find strong evidence for them.

The structure of the paper is as follows. Section 2 discusses the data and provides descriptive statistics. Section 3 elaborates on the estimation techniques and Section 4 discusses the results. Section 5 concludes.

\section{The data and descriptive statistics}

\subsection{The data and selections}

Our log data refer to the economics students' use of university computers located in nine computer rooms that are all in one building of the VU University, Amsterdam. ${ }^{5}$ Information

\footnotetext{
${ }^{5}$ The Economics Department had 3,874 student registrations for the academic year 2008 - 2009. Including floor space costs, annual costs are about $€ 1,200$ per computer. The computers are used, on average, 3.5 hours per day, so the costs are about $€ 1.50$ per hour of use. The annual costs per student are about $€ 67$.
} 
monitors in corridors provide information on the number of vacant computers per room. ${ }^{6}$ We employ computer use data from January 2008 to April 2009. So, we know for each student which computer is used at what time. For analysing computer hoarding, it is important to make a distinction between voluntary and involuntary outflow. Involuntary outflow occurs when a computer room is closed in the late afternoon or evening, forcing students to move to other rooms. Because we are interested in voluntary outflow, we select data about computer use before $3 \mathrm{pm}$.

We make two additional data selections. First, we exclude 105 holidays and examination days in order to avoid identification based on atypical days. Second, we exclude students who participate in computer-aided lectures during that day, as for these students, our identification strategy that relies on exogenous variation in computer supply might be invalid (these students are likely to flow out in order to use reserved computers during computer lectures). Given these data selections, we observe computer use by 3,369 students during 206 weekdays. We measure computer use, so inflow and outflow behaviour, per 15-minutes intervals. In total, we have 412,178 observations over 5,448 intervals.

\subsection{Descriptive statistics}

Table 1 provides descriptive statistics on computer use. The average aggregate inflow (per 15 minutes) is 14 users (on average, the aggregate outflow is slightly lower, because at 3pm, there are still 54 users, on average). The outflow rate per student (per 15 minutes) is 0.176 , corresponding to an average session duration of 85 minutes. The reported occupancy rate reflects the occupancy of computers available to students (so excluding computers in rooms that are reserved for lectures).

In total, there are 217 computers. The number of computers that are out of order is unknown, but, in general, only very few computers are out-of-order, which implies that we

\footnotetext{
${ }^{6}$ The monitors do not contain information on computers that are out-of-order or on future availability of computers.
} 
underestimate occupancy rate slightly. For example, we observe maximally 215 (nonreserved) computers occupied at the same time, so slightly less than maximum capacity. ${ }^{7}$ Of the 217 computers, on average 83 are used by students, 27 are reserved for lectures (and not available to students) and 107 are vacant. The average occupancy rate per user is 0.622 . Frequently, the occupancy rate is very high. For example, in 30 percent of our observations, it exceeds 0.80 (see Figure A1). On many days, at least once during a 15-minutes time interval, occupancy is high. For example, on almost half of the days, the occupancy rate exceeds 0.90 , and in one of five days, it exceeds 0.95 .

Table 1: Descriptive statistics

\begin{tabular}{lcccc}
\hline & Mean & Std. dev. & Min & Max \\
\hline Inflow (aggregate) & 14 & 10 & 0 & 161 \\
Outflow (aggregate) & 12 & 10 & 0 & 83 \\
Outflow rate (per user) & 0.176 & 0.141 & 0 & 1 \\
Occupied computers by students & 83 & 55 & 0 & 215 \\
Reserved computers (instrumental variable) & 27 & 40 & 0 & 182 \\
Vacant computers & 107 & 67 & 0 & 217 \\
Occupancy rate (non-reserved rooms; per user) & 0.622 & 0.245 & 0 & 1 \\
\hline
\end{tabular}

Note: based on 15 minutes time intervals

Students use computers rather infrequently: on average, students use computers on one out of nine weekdays. However, importantly, multiple use on the same day is common: conditional on use on a given day, 34 percent of users have multiple sessions (see Table 2) and 11 percent have at least three sessions. These results indicate that additional computer use later on the same day is important, which makes hoarding behaviour likely when the occupancy is high.

Table 2: Daily number of sessions conditional on use

\begin{tabular}{llllll}
\hline Number of sessions & 1 & 2 & 3 & 4 & 5 or more \\
Frequency (\%) & 66 & 22 & 7 & 3 & 1 \\
\hline
\end{tabular}

Note: information based on 83,801 computer-use days

\footnotetext{
${ }^{7}$ Another reason why we do not observe non-reserved computers being used to their full capacity is that some computers are usually reserved for lectures. For example, around one o'clock, which is a peak period, at least one computer room is reserved about half of the time.
} 
The occupancy rate fluctuates strongly over the day: it is highest by the end of the morning and beginning of the afternoon (see Figure A2 in the Appendix). ${ }^{8}$ The occupancy rate is strongly autocorrelated: the correlation of the occupancy rate with the rate one hour later is 0.60 (conditional on hour of the day, week, and day fixed effects). This makes it likely that students use the current level of occupancy rate to predict future occupancy.

To understand the statistical relationship of the current occupancy rate with the future rate, we have regressed the occupancy rate on its (one-hour) lag and the square of this lag. It appears that the coefficients are 0.86 (s.e. 0.03 ) and -0.23 (s.e. 0.03 ) respectively. So, the current occupancy rate has a less than proportional effect on the future occupancy rate. Furthermore, it thus appears that this effect is concave (this makes sense because the occupancy rate is less than one and therefore has a finite variance). For example, when the occupancy rate is 0.62 (the average), the marginal effect is 0.57 , and the marginal effect is 0.40 when the occupancy rate reaches 1 .

In the introduction we mentioned that many students prefer to sit in groups (so students may hoard computers even when the occupancy rate of computers is substantially less than one). To demonstrate this, we have estimated models (for one computer room containing 30 computers) to show that students with similar characteristics sit together in computer rooms. For example, we have estimated linear probability models which show that the probability that the user is a master student increases by about 0.1 when another master student is using one of the adjacent computers (either to the left, or to the right). In these models, we include hour dummies to control for the share of master students per hour. The results are provided in Table A1 of the Appendix. Similar results are obtained if we do not focus on master students, but on other types of students that are more likely to sit together

\footnotetext{
${ }^{8}$ This is in line with Spennemann et al. (2007) and Tang and Baker (2000).
} 
(e.g., the year during which the student commenced his/her study, the course in which the student is registered).

\section{Estimation methods}

\subsection{Identification and local treatment effects}

Hoarding can be modelled by assuming that utility-maximising individuals use a computer at $t$ but prefer to stop using the computer until $t+s$ (e.g., to have a break). The occupancy rate at $t$ is denoted by $X_{t}$, where $0 \leq X_{t} \leq 1$. The individual decides whether to continue using the computer (hoarding strategy) or to leave the computer and return later on at $t+s$, where $\mathrm{s}>0$. The cost of entry at $t+s$, denoted by $\mathrm{C}_{\mathrm{t}+\mathrm{s}}$, are assumed to depend positively on the occupancy rate at the moment of re-entry, denoted $X_{t+s}$. We assume that the occupancy rate $X_{t}$ is positively correlated over time, so the expected costs of entry at $t+s$ depend on the occupancy rate at $t$. For example, when occupancy follows a random walk, then the expected cost $\mathrm{C}_{\mathrm{t}+\mathrm{s}}$ is $\mathrm{C}_{\mathrm{t}+\mathrm{s}}\left(\mathrm{X}_{\mathrm{t}}\right)$. When the utility function is additive and has a random component, then the probability of hoarding at $t$ depends positively on congestion levels, $\mathrm{X}_{\mathrm{t}}$. In the current paper, the probability of computer hoarding is determined by the computer outflow rate.

We estimate the effect of the occupancy rate on the computer outflow rate, using linear and semiparametric regression models. ${ }^{9}$ Here, $t$ refers to a 15 minutes time interval (so, we ignore variation in occupancy rate within the interval). Our dependent variable, $S_{i t}$, is a dummy indicator whether the student leaves the computer during the time interval of observation.

In the analysis, we include student fixed effects and room fixed effects (as different regulations apply in rooms regarding silence). In addition, we control for elapsed computertime (using a flexible 15 minutes interval dummy specification). Moreover, we interact two-

\footnotetext{
${ }^{9}$ These models are less efficient than maximum likelihood based models (e.g., hazard models or logit models), which are cumbersome to estimate given the large number of fixed effects. Given the large number of observations, efficiency of estimation is not our main concern.
} 
hours dummies (e.g., 8:00 - 10:00 am) with weekday (e.g., Monday) and study semester (e.g., September and October, 2008). In this way, we control for time-varying unobserved aggregate heterogeneity, including students' course schedules which vary over time in a regular way (e.g., third-year bachelor students have Public Economics lectures on Wednesday morning in the fall). We emphasise that it is potentially relevant to control for time-varying aggregate heterogeneity, because the occupancy rate is an aggregate variable which varies over time.

It is also important to instrument for the occupancy rate, $X_{t}$. Endogeneity of $X_{t}$ may be present in our estimates due to unobserved factors (that may affect both $\mathrm{X}_{\mathrm{t}}$ and the outflow rate). In addition, and more importantly, endogeneity may be present because $\mathrm{X}_{\mathrm{t}}$ is the result of outflow behaviour. For that reason, we use the number of computers that are reserved for lectures as an instrumental variable. So, the identification assumption is that there is no direct effect of the number of reserved computers on the outflow of computer users in the nonreserved rooms. One reason why there may be a direct effect of the number of reserved computers on the outflow is when the number of computer lectures is correlated with the number of other (non-computer) lectures. Given the many time-controls included in the model, we believe that this is very unlikely to occur. In addition, we will show in the sensitivity analysis that including additional time controls hardly changes the results, which indicates that this bias is extremely limited. We emphasise that this bias, if present, would lead to an underestimate of the hoarding effect. Hence, our estimates on the congestion elasticity of computer duration are, if anything, on the conservative side.

\subsection{Parametric estimation}

In the parametric estimates, we will assume that the occupancy rate, $\mathrm{X}_{\mathrm{ticr}}$, is linearly related to the outflow probability, $S_{i t}$. Let $\eta_{\mathrm{t}}$ denote fixed effects of interactions between two-hours dummies, weekday and study semester, $\theta_{\mathrm{i}}$ captures student fixed effects, $\kappa_{\mathrm{c}}$ and $\lambda_{\mathrm{r}}$ denote elapsed computer duration and room fixed effects. The model we will estimate is then: 


$$
\mathrm{S}_{\mathrm{ticr}}=\beta \mathrm{X}_{\mathrm{ticr}}+\eta_{\mathrm{t}}+\theta_{\mathrm{i}}+\kappa_{\mathrm{c}}+\lambda_{\mathrm{r}}+\varepsilon_{\mathrm{ticr}}
$$

where $\beta$ is the parameter of interest and $\varepsilon_{\text {ticr }}$ denotes an error term.

A potential objection to (1) is that, due to a queuing mechanism, students who flow in during moments of peak occupancy may have a high computer need, which may in turn be correlated with longer computer durations (and therefore a lower quitting probability). To avoid this potential endogeneity problem, we control for the occupancy rate during the moment of login, denoted $X_{0 \mathrm{icr}}$. So, we include the terms $\beta \mathrm{X}_{\mathrm{ticr}}$ and $\zeta \mathrm{X}_{0 \mathrm{icr}}$, where $\beta$ and $\zeta$ are coefficients to be estimated. This specification is identical to a specification with $\gamma \mathrm{X}_{\text {ticr }}+$ $\delta\left[\mathrm{X}_{0 \mathrm{icr}}-\mathrm{X}_{\text {ticr }}\right]$, where $\beta=\gamma-\delta$. We continue to assume that $\mathrm{X}_{0 \mathrm{icr}}$ is endogenous, but we assume that the term $\left[\mathrm{X}_{0 \mathrm{icr}}-\mathrm{X}_{\mathrm{ticr}}\right]$ is exogenous, which seems a reasonable assumption because the computer outflow rate at $t$ is unlikely to depend on the change in $\mathrm{X}_{\text {ticr }}$ over time.

So, in addition to (1), we estimate the following equation:

$$
\mathrm{S}_{\mathrm{ticr}}=\gamma \mathrm{X}_{\mathrm{ticr}}+\delta\left[\mathrm{X}_{0 \mathrm{icr}}-\mathrm{X}_{\mathrm{ticr}}\right]+\eta_{\mathrm{t}}+\theta_{\mathrm{i}}+\kappa_{\mathrm{c}}+\lambda_{\mathrm{r}}+\varepsilon_{\mathrm{ticr}} \text {, }
$$

where $\gamma$ and $\delta$ are estimated directly in the regression equation, and $\beta=\gamma-\delta$ is the parameter of interest.

\subsection{Semiparametric estimation}

Our parametric estimates rely on a the assumption that the effect of $\mathrm{X}_{\text {ticr }}$ on $\mathrm{S}_{\text {ticr }}$ is linear. This assumption may however be inappropriate, for example when hoarding is only important for high occupancy rates. So, we will also estimate semiparametric models. One complication is that when the relationship between $\mathrm{X}_{\text {ticr }}$ and $\mathrm{S}_{\text {ticr }}$ is of an unknown form, one cannot use standard instrumental variable techniques.

In our semiparametric estimates, we employ a control function approach to control for endogeneity of $\mathrm{X}_{\mathrm{ticr}}$ (see Blundell and Powell, 2003; Yatchew, 2003). ${ }^{10}$ This approach treats

\footnotetext{
${ }^{10}$ In linear models, the control function approach, instrumental variables, and plugging in fitted values in the second stage are identical. The (intuitive) approach to plug fitted values of the first stage into the second stage leads to inconsistent estimates for semiparametric functions (Ameniya, 1974; Angrist and Pischke, 2009).
} 
endogeneity as an omitted variable problem, comparable to Heckman's correction for selectivity bias, through the introduction of a control function (Heckman, 1979). An important prerequisite of the control function approach is that the endogenous variable must be (approximately) continuously distributed, which is fulfilled in our application (see Figure A1). The procedure to apply the control function is to first regress the endogenous independent variable on all independent variables and instruments. The predicted errors of this step are used as a semiparametric control function that is additive to the dependent variable in the second stage. We denote the instrument by $\mathrm{P}_{\mathrm{t}}$. The first stage is then:

$$
\mathrm{X}_{\text {ticr }}=\Delta\left(\mathrm{P}_{\text {ticr }}\right)+\delta\left(\mathrm{X}_{0 \mathrm{icr}}-\mathrm{X}_{\text {ticr }}\right)+\eta_{\mathrm{t}}+\theta_{\mathrm{i}}+\kappa_{\mathrm{c}}+\lambda_{\mathrm{r}}+\xi_{\text {ticr }}
$$

where $\Delta(\cdot)$ denotes a nonparametric function of $\mathrm{P}_{\text {ticr }}$, and $\xi_{\text {ticr }}$ denotes the first-stage error term. We estimate $\Delta(\cdot)$ using series approximation, so we write $\Delta(\cdot)=\sum_{n=1}^{N} \alpha_{n} P_{\text {ticr }}^{\mathrm{n}}$ where $\alpha_{n}$ are parameters to be estimated and $n$ denotes the order of the polynomial to be estimated. The second stage encompasses:

$$
\mathrm{S}_{\mathrm{ticr}}=\Gamma\left(\mathrm{X}_{\mathrm{ticr}}\right)+\delta\left(\mathrm{X}_{0 \mathrm{icr}}-\mathrm{X}_{\mathrm{ticr}}\right)+\Lambda\left(\xi_{\text {ticr }}\right)+\eta_{\mathrm{t}}+\theta_{\mathrm{i}}+\kappa_{\mathrm{c}}+\lambda_{\mathrm{r}}+\varepsilon_{\mathrm{ticr}},
$$

where $\Gamma(\cdot)=\sum_{\mathrm{n}=1}^{\mathrm{N}} \beta_{\mathrm{n}} \mathrm{X}_{\text {ticr }}^{\mathrm{n}}$ and $\Lambda(\cdot)=\sum_{\mathrm{n}=1}^{\mathrm{N}} \varphi_{\mathrm{n}} \xi_{\text {ticr }}^{\mathrm{n}}$ and $\beta_{\mathrm{n}}$ and $\varphi_{\mathrm{n}}$ are parameters to be estimated. $^{11}$

We estimate the semiparametric functions using fifth-order polynomials, so $\mathrm{N}=5$. The results are very similar for a different choice of $\mathrm{N}$. The standard errors are obtained by a bootstrapping procedure. $^{12}$

In our semiparametric estimation procedure, we select observations with an occupancy rate higher than 30 percent, because it is not insightful to study the local treatment effect when the computer rooms are almost completely empty, and including these observations strongly

\footnotetext{
${ }^{11}$ The marginal effect is calculated as $\partial \mathrm{S}_{\text {ticr }} / \partial \mathrm{X}_{\mathrm{ticr}}=\partial \Gamma(\cdot) / \partial \mathrm{X}_{\mathrm{ticr}}-\delta=\sum_{\mathrm{n}=1}^{\mathrm{N}} \mathrm{n} \beta_{\mathrm{n}} \mathrm{X}_{\text {ticr }}^{\mathrm{n}-1}-\delta$.

${ }^{12}$ We use 250 bootstrap replications. To calculate the standard errors, we take into account that $\mathrm{N}$ is in principle unknown. For each bootstrap replication we draw $\mathrm{N}$ from a uniform distribution, where $\mathrm{N}=\mathrm{U}[3,7]$. This leads to an overestimate of the standard errors if $\mathrm{N}=5$ is correct. So, our test of a congestion effect is conservative. For values of $\mathrm{N}$ lower than 3 , the function is not flexible enough to capture nonlinearities. For values larger than 7 , multicollinearity occurs.
} 
inflates standard errors (there are few observations with an occupancy rate less than 30 percent). For the parametric estimation, we will show that this data selection does not influence the estimated effect of congestion.

\section{The empirical results}

\subsection{Parametric estimate on outflow}

Table 4 reports the effect of current occupancy, $X_{t}$, on the probability that a user flows out (during a 15-minutes interval) for several specifications. ${ }^{13}$ We emphasise that the instrument, the number of reserved computers, is strong. ${ }^{14}$

In column [1], we show the results of a specification where we control for student fixed effects, as well as two-hours dummies interacted with weekday and study semester. The effect is -0.1364 (with a standard error of 0.0143 ). In column [2],we also control for elapsed computer time and room fixed effects. The effect is now somewhat smaller: the effect is now 0.1095 (s.e. 0.0117). In column [3], we also include $\left[\mathrm{X}_{0}-\mathrm{X}_{\mathrm{t}}\right.$, so we control for the occupancy rate at the time of login, $\mathrm{X}_{0}$. We emphasise that we are now interested in the overall effect of current occupancy rate, $X_{t}$, reported at the bottom of the table. The effect is now -0.0921 (s.e. 0.0100), so only slightly lower than the previous specifications. These results also hold when we exclude observations when the occupancy rate is small. For example, column [4] shows that excluding observations when the occupancy rate is less than 30 percent, the results hardly change. $^{15}$

The results of Table 3 imply that users are less likely to flow out at moments of higher occupancy, which provides strong evidence of computer hoarding. ${ }^{16}$ To be more precise, our

\footnotetext{
${ }^{13}$ For convenience, we refer now to $\mathrm{X}_{\text {ticr }}$ as $\mathrm{X}_{\mathrm{t}}$ and $\mathrm{X}_{0 \text { icr }}$ as $\mathrm{X}_{0}$.

${ }^{14}$ An F-test of the strength of the instrument indicates that the F-value is 503, so far above the minimum of 10 usually recommended. The first stage coefficient of $X_{t}$ is positive and is equal to 0.002014 (s.e. 0.000001).

15 This is important because we focus on occupancy rates above 30 percent in the semiparametric specification.

${ }^{16}$ There may also be a slight positive effect, when congested rooms are considered less comfortable, so hoarding is underestimated. High occupancy may also be thought to cause the internet to run slower (which may increase
} 
estimates imply that a 10 percent increase in occupancy decreases the outflow probability by roughly one percent point, thus about 5.7 percent of the mean outflow rate. This implies that the congestion elasticity of computer duration is about 0.57. A longer computer duration increases congestion, so hoarding creates congestion externalities to new users, at least during peak-hours. Hence, our findings favour congestion pricing of computer use (as suggested in the context of parking, by Vickrey in 1954). Because congestion pricing may be difficult to implement for university computers, a second-best policy which puts limits on computer duration might be considered, despite the other inefficiencies created by such limits (Calthrop, 2001; Arnott and Rowse, 2009b).

Table 3: Parametric estimate on outflow probability

\begin{tabular}{lllll}
\hline & \multicolumn{1}{c}{$[1]$} & \multicolumn{1}{c}{$[2]$} & \multicolumn{1}{c}{$[3]$} & \multicolumn{1}{c}{$\mathrm{X}_{\mathrm{t}}>0.3$} \\
\hline Data selection & & & & $-0.0918^{* * *}$ \\
$\mathrm{X}_{\mathrm{t}}$, occupancy rate & $-0.1364^{* * *}$ & $-0.1095^{* * *}$ & $-0.1216^{* * *}$ & $-0.0177)$ \\
$\mathrm{X}_{0}-\mathrm{X}_{\mathrm{t}}$ occupancy rate difference & $(0.0143)$ & $(0.0117)$ & $(0.0134)$ & $(0.017)^{*}$ \\
& & & $-0.0294^{* * *}$ & $-0.0107^{*}$ \\
Two hours interval fixed effects (180) & Yes & Yes & $(0.0061)$ & $(0.0064)$ \\
Student fixed effects (3,335) & Yes & Yes & Yes & Yes \\
Elapsed computer time dummies (28) & No & Yes & Yes & Yes \\
Room dummies (9) & No & Yes & Yes & Yes \\
Number of observations & 412,178 & 412,178 & 412,178 & 362,288 \\
\hline Overall effect of $X_{t}$ & $-0.1364^{* * *}$ & $-0.1095^{* * *}$ & $-0.0921^{* * *}$ & $-0.0811^{* * *}$ \\
& $(0.0143)$ & $(0.0117)$ & $(0.0100)$ & $(0.0136)$ \\
\hline
\end{tabular}

Note: standard errors in parentheses; ${ }^{* * *} \mathrm{p}<0.01 ;{ }^{*} \mathrm{p}<0.1$.

\subsection{Sensitivity analyses}

One point of concern is that computer congestion may impede students to move to more favourable computers (e.g., less noisy). This 'undesirable computer' effect could be an alternative explanation for our findings. ${ }^{17}$ To test for this, we have re-estimated the model on a sample which excludes 35,000 observations of computer users who use two different

or decrease the outflow probability). This second effect is likely negligible, because the university internet connection is equipped for a much larger group than economics students.

${ }^{17}$ A priori, one expects the alternative explanation not to be of importance, in particularly because we have included computer rooms fixed effects, so the undesirable computer effect mainly applies to within-room variation of computers. 
computers within a short time period (either in the same room within 5 minutes or another room within 10 minutes). We then obtain an almost identical effect of -0.0847 (s.e. 0.012). ${ }^{18}$

Another point of concern with our identification strategy may be that our instrumental variable, the number of computers that are reserved for computer lectures, may be correlated with the number of other lectures. Our exclusion restriction may then be invalid, because users may log off to attend lectures. We are not too concerned about this because the bias would likely lead to an underestimate of hoarding. More importantly, the bias must be minimal, because we include many time dummies which control for regular time patterns in congestion. Nevertheless, we have tested for this by estimating the model with even more controls (in particular, week and year combination dummies, e.g. week 1 in 2008), and without time controls, but the results hardly change (i.e., -0.1094, s.e. 0.0107 and -0.1163 , s.e. 0.0093, respectively). This strongly suggests this bias is extremely limited.

\subsection{Semiparametric estimate on outflow}

The effect of the occupancy level on computer outflow depends, among others, on the autocorrelation of occupancy over time. The functional form of the effect of occupancy on computer outflow is unknown. A priori, one may imagine that the effect of occupancy on computer outflow is convex, because at low occupancy rates, the (marginal) hoarding effect must be close to zero and becomes negative for higher levels of occupancy. However, we have seen above that the effect of occupancy rate on the future occupancy rate is concave. This makes it less plausible that the occupancy rate has a convex effect on the probability of hoarding, and even allows for the possibility that the effect is concave.

In order to estimate the total effect of $\mathrm{X}_{\mathrm{t}}$ for different levels of $\mathrm{X}_{\mathrm{t}}$, we have applied semiparametric regression techniques, see (4). We use the same control variables as before (see, column [4] of Table 3). The estimated total effect of the occupancy rate is presented in

\footnotetext{
${ }^{18}$ When we exclude 22,837 observations of students who conducted resets (i.e. logged on to the same computer within 5 minutes of the last logoff), we find that the effect is -0.0886 (s.e. 0.0104 ).
} 
Figure 1, which indicates that there is no effect up to 0.5 , in line with the idea that hoarding is not important for low levels of congestion. For occupancy rates higher than 0.5 , the total effect follows roughly a linear specification. ${ }^{19}$ Consequently, this suggests that the effect of occupancy rate is convex over the whole interval, but approximately linear for higher levels.

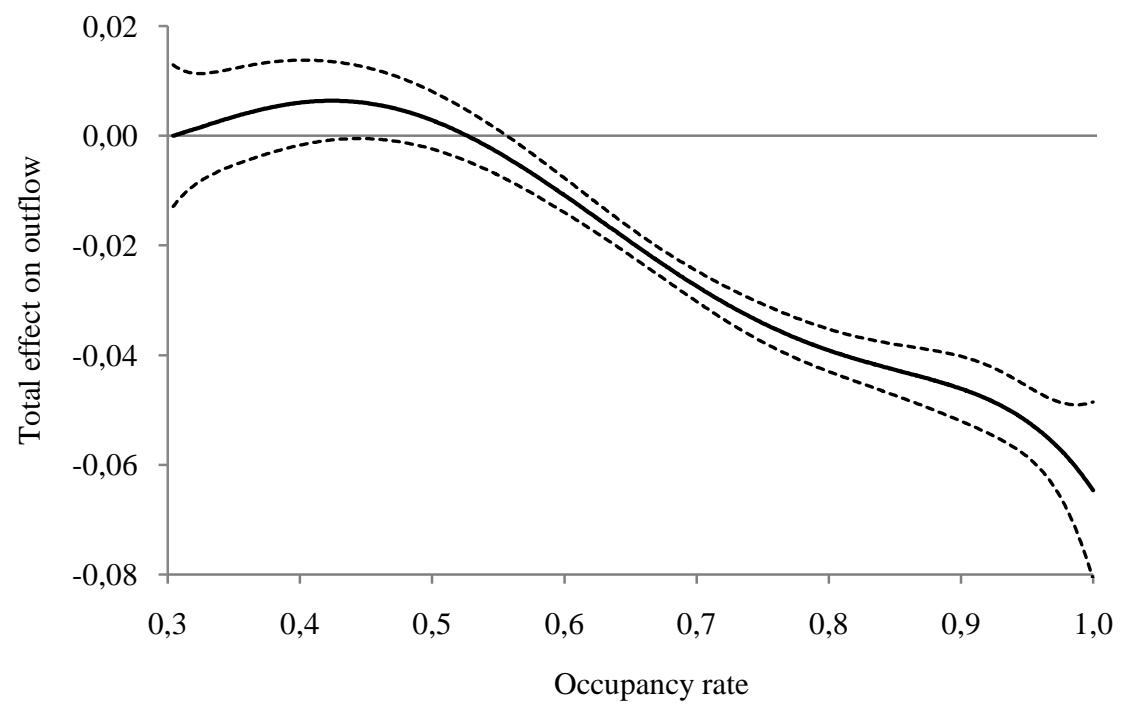

Figure 1: Effect of occupancy rate on outflow probability (with 95\% conf. interval)

Because the number of observations with occupancy rates below 0.5 is limited (see Figure A1), the linear model is quite accurate in its estimates. Consequently, the semiparametric and parametric estimates provide similar insights about the presence of hoarding.

\section{Conclusion}

We have argued that for certain types of goods, congestion may induce current users to lengthen their period of use, to reserve a place for later. We have tested for hoarding of university computers by students. Using parametric and semiparametric regression models, we have shown that computer occupancy rates have a strong positive effect on computer use duration. Our results show that the congestion elasticity of computer duration is about 0.57 .

\footnotetext{
${ }^{19}$ We also estimated models excluding $\mathrm{X}_{0}-\mathrm{X}_{\mathrm{t}}$, which leads to almost identical results.
} 


\section{References}

Ameniya, T. (1974), The nonlinear two-stage least squares estimator. Journal of Econometrics, 2, 105-110.

Anderson, S.P. and A. de Palma (2004), The economics of pricing parking. Journal of Urban Economics, $55,1-20$.

Angrist, J.D. and J.S. Pischke (2009), Mostly Harmless Econometrics: An Empiricists Companion. Princeton University Press, Princeton.

Arbatskaya, M., K. Mukhopadhaya, and E. Rasmusen (2007), The parking lot problem. Available at www.bus.indiana.edu.

Arnott, R. and E. Inci (2006), An integrated model of downtown parking and traffic congestion. Journal of Urban Economics, 60, 418-42.

Arnott, R. and J. Rowse (1999), Modeling parking. Journal of Urban Economics, 45, 97-124.

Arnott, R. and J. Rowse (2009a), Downtown parking in auto city. Regional Science and Urban Economics, 39, 1-14.

Arnott, R. and J. Rowse (2009b), Curbside parking time Limits. Available at http://cssd.ucr.edu/.

Atkinson, A.B. and J.E. Stiglitz (1980), Lectures on Public Economics. McGraw-Hill, New York and London.

Blundell, R. and J.L. Powell, (2003), Endogeneity in Nonparametric and Semiparametric Regression Models. In: M. Dewatripont, L.P. Hansen and S.J. Turnovsky (eds), Advances in Economics and Econometrics: Theory and Applications. Cambridge University Press, Cambridge.

Burke, L., L. Beranek, A. Nolan, G. Walton, R. Stubbings and G. Brewerton (2008), Where and why students choose to use computer facilities: a collaborative study at an Australian and United Kingdom university. Australian Academic \& Research Libraries, 39, 181.

Calthrop, E. (2001). Essays in urban transport economics, PhD Thesis 151, Leuven.

Currie, J. and A. Yelowitz (2000), Are public housing projects good for kids? Journal of Public Economics, 75, 99-124.

Doganis, R. (2002), Flying off-course - The economics of international airlines. Routledge, London.

Gilbert, D. and S. Hudson (2000), Tourism demand constraints: A skiing participation. Annals of Tourism Research, 27, 906-25. 
Givoni, M. and P. Rietveld (2009). Airline's choice of aircraft size - explanations and implications, Transportation Research A, 43, 500-10.

Glaeser, E.L. and E.F.P. Luttmer (2003), The Misallocation of Housing Under Rent Control. American Economic Review, 93, 1027-46.

Heckman, J.J. (1979), Sample selection bias as a specification error. Econometrica, 47, 931-59.

Henderson, T., D. Kotz and I. Abyzov (2008), The changing usage of a mature campus-wide wireless network. Computer Networks, 52, 2690-712.

Kotz, D. and K. Essien (2005), Analysis of a campus-wide wireless network. Wireless Networks, 11, 11533.

Lyons, G. and J. Urry (2005), Travel time use in the information age. Transportation Research Part A, 39, 257-76.

Ohmori, N. and N. Harata (2008), How different are activities while commuting by train? A case in Tokyo. Tijdschrift voor Economische en Sociale geografie, 99, 547-61.

Olsen, E.O. and D.M. Barton (1983), The benefits and costs of public housing in New York City. Journal of Public Economics, 20, 299-332.

Proost, S. and K.V. Dender (2008), Optimal urban transport pricing in the presence of congestion, economies of density and costly public funds. Transportation Research Part A: Policy and Practice, 42, 1220-30.

Scotchmer, S. (2002), Local public goods and clubs. In: A.J. Auerbach and M. Feldstein, Handbook of Public Economics, vol. 4, Elsevier, Amsterdam.

Sevtsuk, A., S. Huang, F. Calabrese and C. Ratti (2009), Mapping the MIT campus in real time using WiFi. Handbook of Research on Urban Informatics: The Practice and Promise of the Real-Time City. IGI Global.

Shoup, D.C. (2005), The High Costs of Free Parking. American Planning Association, Chicago.

Small, K.A. and E.T. Verhoef (2007), The Economics of Urban Transportation, 2 ed. Routledge Taylor \& Francis Group, London and New York.

Spennemann, D.H.R., J. Atkinson and D. Cornforth (2007), Sessional, weekly and diurnal patterns of computer lab usage by students attending a regional University in Australia. Computers \& Education, 49, 726-39. 
Straathof, M. (2011), Dringen voor een plek in de studeertempel. Het Parool [Amsterdam], (11 Jun 2011).

Tang, D. and M. Baker (2000), Analysis of a local-area wireless network. Proceedings of the $6^{\text {th }}$ annual international conference on mobile computing and networking.

Van Ommeren, J.N. and M.J. Koopman (2011), Public housing and the value of apartment quality to households. Regional Science and Urban Economics, 41, 207-13.

Vickrey, W.S. (1954), The economizing of curb parking space, Traffic Engineering, 62-67, reprinted in Journal of Urban Economics, 36, 42-65.

Yatchew, A. (2003), Semiparametric Regression for the Applied Econometrician. Cambridge University Press, Cambridge. 


\section{Appendix A: Background Information}

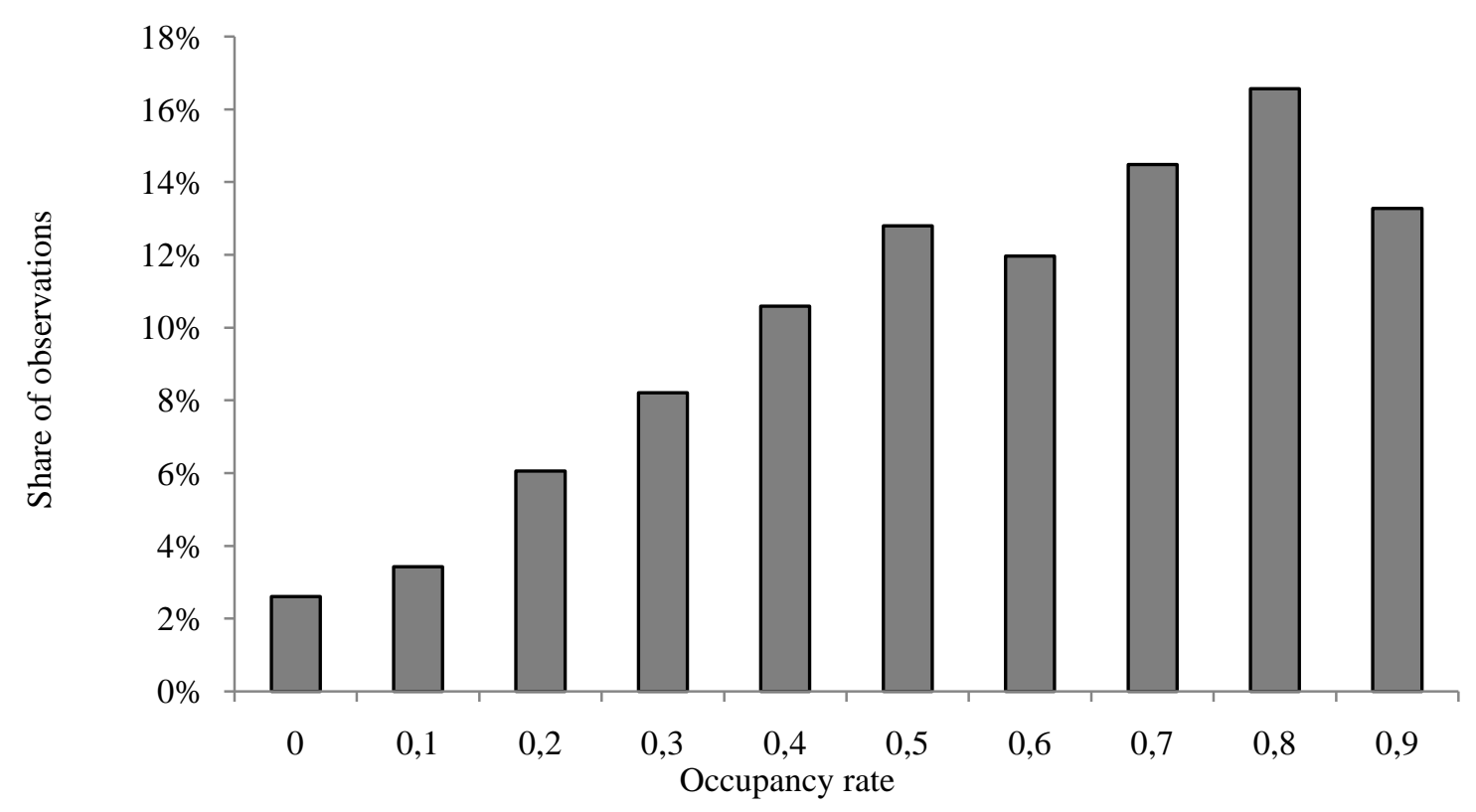

Figure A1: The distribution of occupancy rates

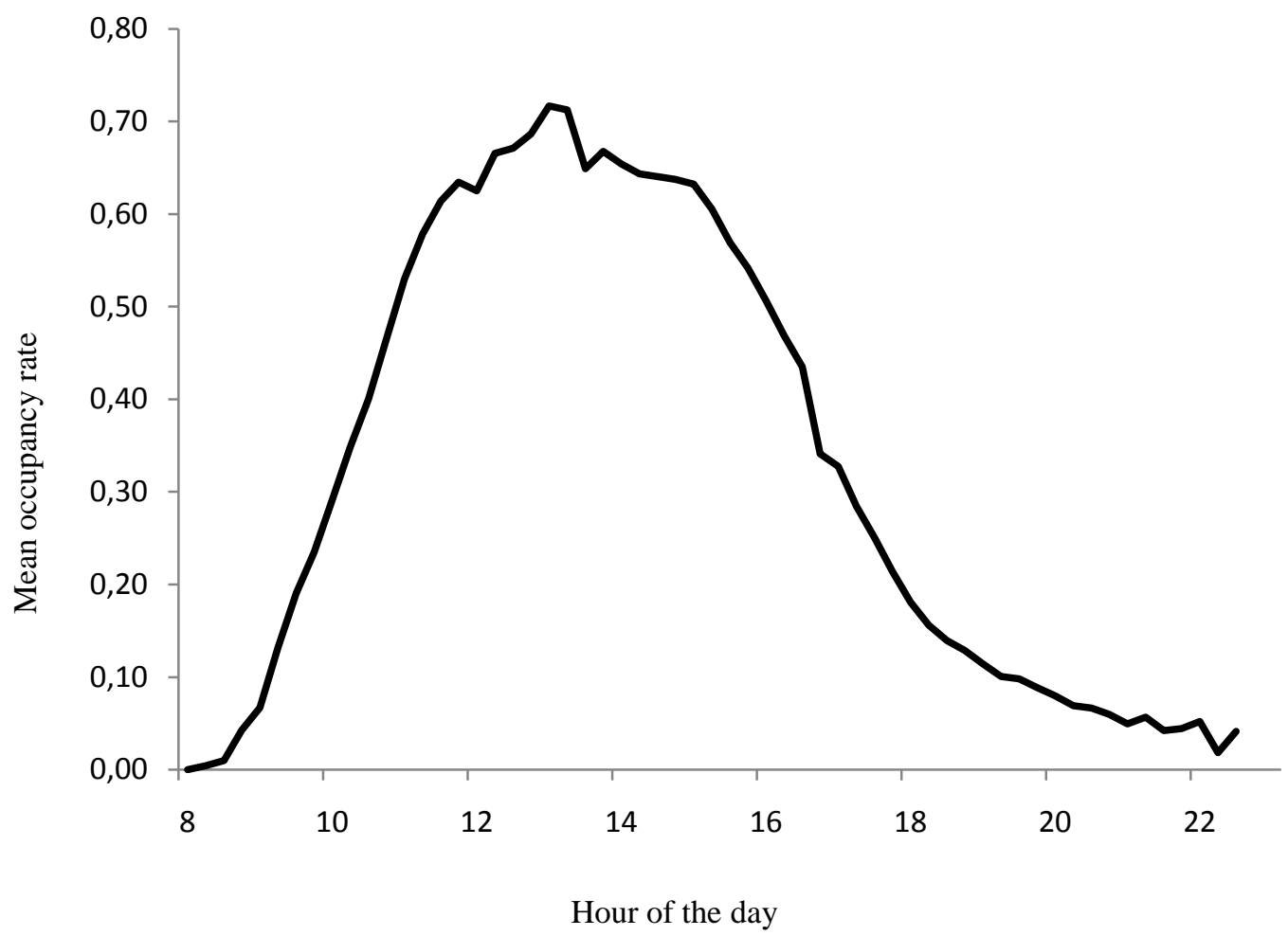

Figure A2: Occupancy level per hour of the day 
Table A1: Probability that computer user is a master student

\begin{tabular}{ll}
\hline User of adjacent left pc is a master student & $0.109^{* * *}$ \\
& $(0.015)$ \\
& $0.082^{* * *}$ \\
User of adjacent right pc is a master student & $(0.015)$ \\
& -0.013 \\
User two pc's to left is a master student & $(0.014)$ \\
& -0.013 \\
User two pc's to right is a master student & $(0.015)$ \\
\hline Hour dummies (1500) & yes \\
Number of observations & 4,821
\end{tabular}

Notes: standard errors in parentheses; ${ }^{* * *} \mathrm{p}<0.01,{ }^{*} \mathrm{p}<0.1$ 